\title{
Low-frequency vibrational modes and infrared absorbance of red, blue and green opsin
}

\section{Saravana Prakash Thirumuruganandham • Herbert M. Urbassek}

Published online: 1 September 2009

(C) Springer-Verlag 2009

\section{Erratum to: J Mol Model}

\section{DOI 10.1007/s00894-008-0446-1}

Unfortunately the figures displaying the infrared absorbance of the opsins discussed in section Infrared absorbance of our paper [1] were missing. They are reproduced below.
As a consequence, the references to Fig. 7 in section Power spectra in vacuo refer to Fig. 6. All other references are valid.

[1] S. P. Thirumuruganandham and H. M. Urbassek, J. Mol. Model. 15, 959 (2009).

\section{Figure caption:}

Infrared absorbance of blue opsin (a) and for the three opsins studied (b).

a

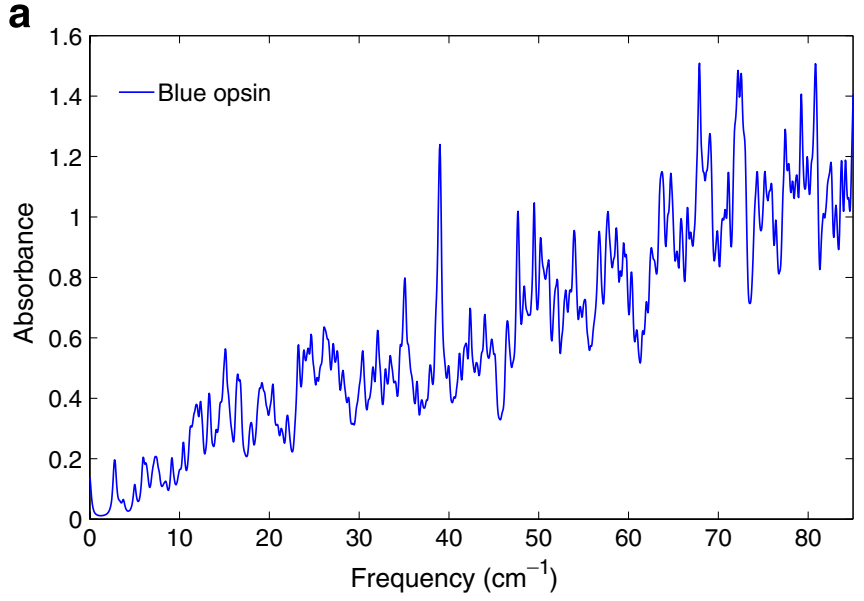

b

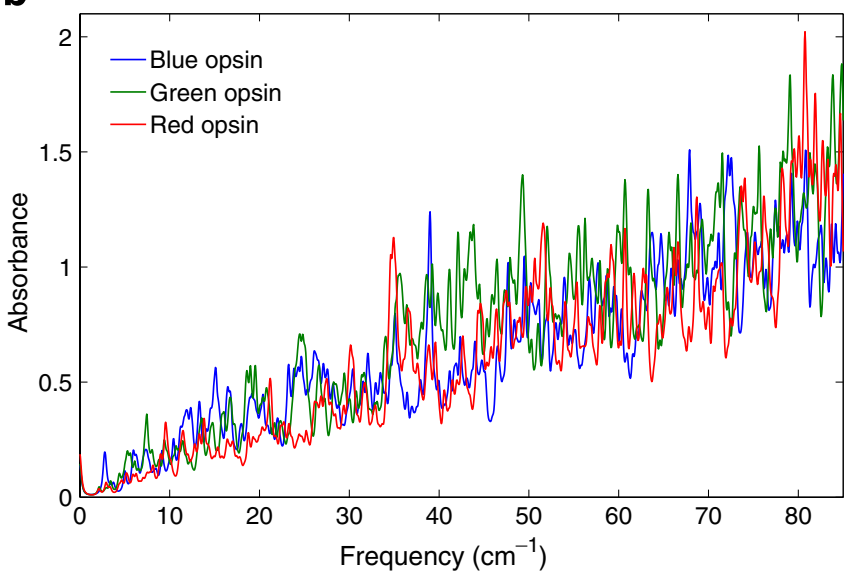

The online version of the original article can be found at http://dx.doi. org/10.1007/s00894-008-0446-1.

S. P. Thirumuruganandham $\cdot$ H. M. Urbassek $(\bowtie)$

Fachbereich Physik und Forschungszentrum OPTIMAS,

Universität Kaiserslautern,

Erwin-Schrödinger-Straße,

67663 Kaiserslautern, Germany

e-mail: urbassek@rhrk.uni-kl.de

URL: http://www.physik.uni-kl.de/urbassek/ 